\title{
Role of Computed Tomography Angiography (CTA) and Color Doppler Ultrasonography in Evaluation of Arterial System in Diabetic Foot
}

\author{
AHMED E. SHABAN, M.Sc.*; KHALED I. EL-SHAFEY, M.D.*; HASSAN A. HASSAN, M.D.** and \\ HAYTHAM H. EMAM, M.D.* \\ The Departments of Radiodiagnosis \& Medical Imaging* and Vascular Surgery**, Faculty of Medicine, Tanta University
}

\begin{abstract}
Objective: The aim of this study was to highlight the role of Computed Tomography Angiography (CTA) and color Doppler Ultrasonography (DUS) in the evaluation of patients with diabetic foot disease.

Background: The risk for ulceration and amputation is much higher in diabetics compared with nondiabetics. CTA is more frequently used to assess peripheral vascular disease of the diabetic foot while Doppler ultrasonograpy is a reliable non-invasive method of investigating the lower limb arterial system provides us with hemodynamic data proximal, distal and at the site of obstruction.

Patients and Methods: This prospective study included 30 diabetic patients who presented with diabetic foot vascular lesions and referred from outpatient clinics of Vascular Surgery Department to the Radiology and Medical Imaging Department, Tanta University Hospital. The present study was performed in the period between March 2017 and March 2018. Their ages ranged from 40 to 80 years; 17 of them were men and 13 were women. All cases underwent Doppler examination as a rapid, noninvasive complementary diagnostic tool, and the findings were compared with those of CTA.
\end{abstract}

Results: In the present study, the number of segments were 513 for 57 limbs, and each arterial tree of one limb was divided into nine segments (common iliac,external iliac, common femoral, superficial femoral, popliteal, anterior tibial, posterior tibial, peroneal, and dorsalis pedis arteries). In this study, the number of stenotic segments was 30 and 22 on Multidetector Computed Tomography Angiography (MDCTA) and DUS, respectively. The number of segments with total occlusion was 50 and 43 on MDCTA and DUS, respectively.

Conclusion: The use of CTA and DUS increases the ability to delineate vascular anatomy, localize the obstruction, assess the severity of stenosis, and detect the presence of collaterals and distal run off.

Key Words: Computed tomography angiography - Diabetic foot-Occlusion.

Correspondence to: Dr. Ahmed E. Shaban, The Department of Radiodiagnosis \& Medical Imaging, Faculty of Medicine, Tanta University

\section{Introduction}

DIABETES mellitus is a growing global epidemic of the twenty-first century. According to the WHO, the number of patients with diabetes type II will rise from 220 million in 2010 to 250 million in 2020 , and 300 million in 2025. One of the major debilitating complications of diabetes is diabetic foot, including the ulcerations and deformities of the foot. Diabetic foot ulcers and infections are common and incur substantial economic problems for society, patients, and families [1] .

Diabetic persons, like people who are not diabetic, may develop atherosclerotic disease of largesized and medium-sized arteries, such as aortoiliac and femoropopliteal atherosclerosis. However, significant atherosclerotic disease of the infrapopliteal segments is particularly common in the diabetic population. Underlying digital artery disease, when compounded by an infected ulcer in close proximity, may result in complete loss of digital collaterals and precipitate gangrene [2] .

\footnotetext{
Abbreviations:

MIP : Maximum Intensity Projection.

MPR : Multiplanar Reconstruction.

MRA : Magnetic Resonance Angiography.

MRI : Magnetic Resonance Imaging.

DUS : Duplex Ultrasound.

CTA : Computed Tomographic Angiography.

PAD : Peripheral Arterial Disease.

MDCT : Multidetector Row Computed Tomography.

SFA : Superficial Femoral Artery.

POPA : Popliteal Artery.

ATA : Anterior Tibial Artery.

PTA : Posterior Tibial Artery.

DPA : Dorsalis Pedis Artery.

PVD : Peripheral Vascular Disease.

WC : Window Center.

WW : Window Width.
} 
Conventional angiography is still regarded as the gold standard for arterial imaging because of its high spatial resolution and the advantage of allowing endovascular therapy during the same procedure. Arterial revascularization can be performed through an endovascular procedure-such as a balloon dilatation [Percutaneous Transluminal Angioplasty (PTA)] or an endovascular (subintimal) recanalization followed by PTA with or without adjunctive stenting [3].

Doppler Ultrasonography (US) is cheap non invasive investigation in the evaluation of lowerextremity arterial disease. A significant atherosclerotic vascular lesion can be detected only by thickening of the vessel wall or segmental narrowing of the lumen (which usually represents plaque or mural thrombus). Spectral Doppler ultrasonography and color-flow vascular imaging supplement study in identifying blood vessels, confirming the direction of blood flow, and detecting sonolucent thrombus, vascular stenosis or occlusion $[4,5]$.

Multidetector-row Computed Tomography Angiography (MD-CTA) is a low invasive imaging modality for Peripherial Arterial Disease (PAD) in diabetic foot. It can be performed with any MDCTA, however, currently 32 to 128 row scanners are used for peripheral MD-CTA, and iodinated contrast media are injected intravenously. For lower extremity PAD, the scan range is from the renal arteries to the foot [6]

Magnetic resonance angiography has several advantages for visualizing the peripheral arterial tree. There is no ionizing radiation exposure to the patient, and the gadolinium-based contrast agent is less nephrotoxic than the iodinated contrast agents used for CTA and DSA images demonstrate the contrast-enhanced anatomy of the arterial lumen [7].

\section{Patients and Methods}

\section{Patients:}

In this prospective study, 30 diabetic patients (17 patients were male and 13 patients were female) with diabetic foot and vascular lesions referred from Vascular Surgery Department to Department of Diagnostic Radiology and Medical Imaging Tanta University Hospitals over a period of 12 months starting from March 2017 to March 2018.

The study protocol was approved by the Research Ethics Committee of the Faculty of Medicine, Tanta University and an informed consent was obtained from all participants in this research after full explanation of the benefits and risks of the procedure.

The age of our selected patients ranged from 40-80 years showing that twenty one patients in this study were above the age of 60 years with mean age 60 years old.

\section{Inclusion criteria:}

- Diabetic patients.

- Symptoms of ischemia (intermittent claudication, rest pain).

- Patients with ischemic ulcers and gangrene.

- Patients with foot cellulites.

- Past history of any vascular surgical intervention of the lower limb (previous debridement, drainage, amputations).

\section{Exclusion criteria:}

- Lactic acidosis.

- Patients with chronic renal failure.

\section{Methods:}

Patients in this study were subjected to:

\section{Clinical assessment:}

1- Proper history taking.

2- Clinical examination.

3- Laboratory investigations:

- Blood glucose level.

- Renal function tests.

4- Radiological examination:

I- Doppler ultrasonography including gray scale, colour Doppler, pulsed Doppler and power Doppler.

II- Multi-slice CT angiography.

\section{Color Doppler ultrasonography:}

Color Duplex imaging was done by Toshiba Aplio 500 and Toshiba nemio MX Ultrasound machine with multi-frequency linear probe.

The femoral arteries were examined with the patient supine while the thigh is abducted, externally rotated and flexed. The common femoral artery is examined in longitudinal and transverse planes down to its bifurcation. Then the deep femoral and superficial femoral arteries are examined in similar way down to the adductor hiatus.

Then, the patient is asked to abduct and external rotate of lower limb to examine the popliteal artery proximal and distal segments and followed down to its bifurcation into the tibio-peroneal trunk and anterior tibial artery. 
The posterior tibial artery is located by placing the transducer in a longitudinal position in the medial aspect of the mid-calf area behind the tibia. The peroneal artery is examined from two approachs: Firstly from a posteromedial approach similar to that used for posterior tibial artery and from the anterolateral approach used for the anterior tibial artery. The anterior tibial artery is examined from an anterolateral approach.

Each limb was examined with duplex sonography prior to CTA, 9 segments in each limb were evaluated namely (CIA, EIA, CFA, profunda femoris artery, SFA (proximal, middle, distal), popliteal $\mathrm{A}$, ant tibial A, post tibial A and peroneal A) and classified into the ilio-femoro-popliteal arterial segments (CIA, EIA, CFA, PFA, SFA and popliteal A) and infrapopliteal arterial segments (ATA, PTA and peroneal A).

\section{Computed tomography angiography:}

At first we explained the examination to the patient. Total immobilization of the patient during the examination is of vital importance.

\section{Scan parameters:}

Computed tomography with angiographic technique was performed using Toshiba Aquilion one 320 slices and GE Optima 128 slices C.T. scanners, the slice thickness: $1.5 \mathrm{~mm}$.

Before starting the imaging, the following steps were be considered:

- For the display of soft tissues, a window level of $40 \mathrm{HU}$ and a window width between 400 and 700 $\mathrm{HU}$ were selected; these provide enough contrast between fat and air. A window level between 40 and $300 \mathrm{HU}$ and a window width between 2400 and $3200 \mathrm{HU}$ were selected for imaging of bony structures.

- Patients were placed in the supine position, feet first position.

- Scanning started at the abdomen and proceeded craniocaudaly (scanning is planned from the level of renal arteries down to the forefoot). Both lower limbs were examined even in cases with unilateral ischemia.

- Contrast administration was performed using power injector (Vistron CT injector). Nonionic water soluble contrast (ultravist 300) was used in all patients using wide bore canula (18-20G) inserted in a big vein. The injected amount was calculated as $1-3 \mathrm{ml}$ of contrast media $/ \mathrm{kg}$ at rate of $3-3.5 \mathrm{cc} / \mathrm{sec}$.
A single low-dose CT image is obtained, without contrast administration, at the level of the celiac axis. A $10-15 \mathrm{~mm}^{2}$ circular region of interest is placed inside the middle of the aortic lumen and this will subsequently measure the Hounsfield units of the aortic lumen on subsequent scanning. At 10 seconds following IV contrast administration, serial low-dose monitoring CT scans are obtained at the same table position (celiac axis level) at 2-second intervals. When the region of interest detects a preset contrast enhancement level (usually a 100$150 \mathrm{HU}$ value), there is automatic triggering of the scanner to acquire images in the desired scan range, from the level of the celiac axis to the feet. This time-efficient method ensures optimal arterial enhancement within the region of interest.

In the scanning protocol of the present study the 2 nd run or "late phase" acquisition was done for all patients.

Image reconstruction and manipulation were performed on a workstation. MPR, MIP, and VRT were done in most of the cases. However, inspection of the axial source images remains an essential part of the assessment.

\section{Results}

Thirty patients with diabetic foot and symptoms suggestive to lower limb ischemia were referred to Radiology Department and Medical Imaging of Tanta University Hospital.

Among the 30 patients included in this study 17 patients were males $(56.6 \%)$ while 13 patients were females (43.4\%) (Table 1).

The age of our selected patients ranged from 40-80 years showing that 21 patients were above the age of 60 years $(70 \%)$ and 9 patients were between 40-60 years (30\%) (Table 5) Fig. (2) with mean age 60 years old.

Table (1): Demographic characteristics of studied patients.

\begin{tabular}{lccc}
\hline \multirow{2}{*}{$\begin{array}{l}\text { Age groups } \\
\text { in years }\end{array}$} & No. of cases & \multicolumn{2}{c}{ Gender } \\
\cline { 3 - 4 } & & Male & Female \\
\hline $40-60$ & 21 & 6 & 3 \\
$60-80$ & $60.5 \pm 12.4$ & $60.04 \pm 13.5$ & $61.2 \pm 10.6$ \\
Mean \pm SD & 30 & 17 & 13 \\
\hline Total & & & \\
\hline
\end{tabular}

This table and Fig. (1) show the largest affected people were males and above 60 years old, this is 
due to high incidence of ischemia and prevalence of atherosclerosis in males and old age.

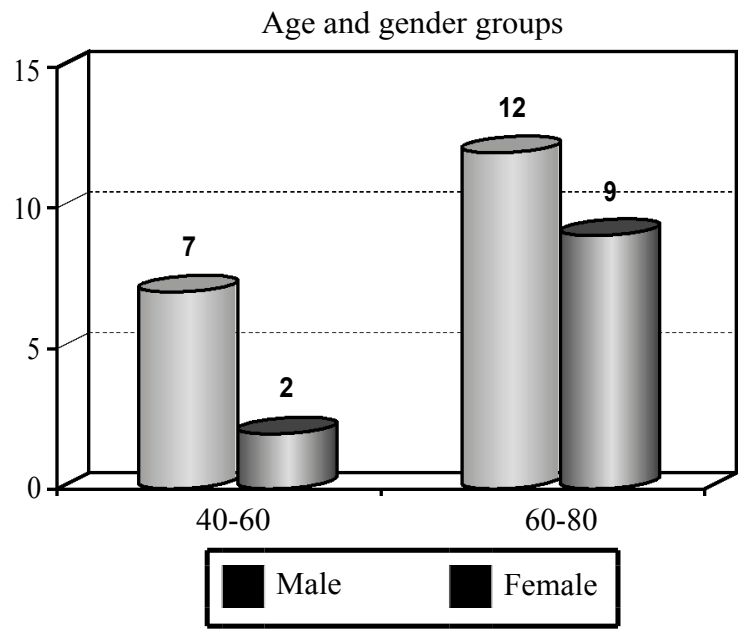

Fig. (1): Age and gender distribution of studied patients.

The overall risk factors were as follows: Age (mean $60.5 \pm 12.4$ years, range $40-80$ years), hypertension was found in 22 patients $(73 \%)$, cigarettes smoking was found in 12 patients $(40 \%)$ and at least coronary heart disease was found in 9 patients $(23 \%)$ (Table 2).

Table (2): Frequency of risk factors in studied patients.

\begin{tabular}{lll}
\hline \multirow{2}{*}{ Risk factors } & \multicolumn{2}{c}{ Total $(\mathrm{n}=30)$} \\
\cline { 2 - 3 } & $\mathrm{N}$ & $\%$ \\
\hline Hypertension & 22 & 73 \\
Smoking & 12 & 40 \\
CHD & 9 & 30 \\
\hline
\end{tabular}

From this table, the major risk factor of peripheral arterial insufficiency of diabetic foot were hypertension which was found in 22 patient.

Regarding the clinical presentation, redness and edema was found in 30 patients intermittent claudication pain was present in 20 patient $(66.6 \%)$, followed by persistent pain and delayed healing foot ulcer was present in 10 patients $(33.3 \%)$, followed by rest pain was present in 6 patients $(20 \%)$ at least amputated leg was present in 3 patients $(10 \%)$ (Table 3$)$.

Table (3): Frequency of clinical presentations in studied patients.

\begin{tabular}{llc}
\hline & \multicolumn{2}{c}{ Total } \\
\cline { 2 - 3 } Clinical presentation & $\mathrm{N}$ & $\%$ \\
\hline Redness and edema & 30 & 100 \\
Intermittent claudication & 20 & 66.6 \\
Persistent pain\& delayed healing foot ulcer & 10 & 33.3 \\
Rest pain & 6 & 20 \\
Amputated leg & 3 & 10 \\
\hline
\end{tabular}

From this table, the most frequent symptoms was redness and edema which found in 30 patients $(100 \%)$ then intermittent claudication which was found in 20 patients $(66.6 \%)$, the least clinical presentation was amputated leg which was found in 3 patients.

Each limb was examined with duplex sonography prior to CTA, 9 segments in each limb were evaluated namely (CIA, EIA, CFA, profunda femoris artery, SFA (proximal, middle, distal), popliteal $\mathrm{A}$, ant tibial A, post tibial $\mathrm{A}$ and peroneal $\mathrm{A}$ ) and classified into the ilio-femoro-popliteal arterial segments (CIA, EIA, CFA, PFA, SFA and popliteal A) and infrapopliteal arterial segments (ATA, PTA and peroneal A) divided the finding of CTA and duplex sonography in to 3 groups for grading of PAD.

A- Total occlusion (100\% diameter reduction) character by no flow is detected in the vessels.

B- Significant stenosis (50-99\% diameter reduction) character by absent of reverse flow component and marked spectral broadening.

C- Non significant stenosis ( $<50$ diameter reduction) character by preserved the reverse flow component and filling of spectral window.

Table (4): Frequency of affected arteries in studied patients by CTA.

\begin{tabular}{|c|c|c|c|c|c|}
\hline \multirow{2}{*}{ Affected arteries } & \multicolumn{2}{|c|}{$\begin{array}{c}\text { Patients } \\
\text { number } \\
(n=30)\end{array}$} & \multicolumn{3}{|c|}{ Segment affection } \\
\hline & $\mathrm{N}^{\mathrm{C}}$ & $\%$ & $\begin{array}{l}\text { Total } \\
\text { occ- } \\
\text { lusion }\end{array}$ & $\begin{array}{l}\text { Significant } \\
\text { stenosis } \\
>50 \%\end{array}$ & $\begin{array}{l}\text { Non- } \\
\text { significant } \\
\text { stenosis }\end{array}$ \\
\hline Common iliac artery & 4 & 7 & 2 & 1 & 1 \\
\hline External iliac artery & 6 & 10.5 & 2 & 3 & 1 \\
\hline Common femoral artery & 2 & 3.5 & 2 & 0 & 0 \\
\hline Profunda femoris artery & 2 & 3.5 & 1 & 1 & 0 \\
\hline Superficial femoral artery & 17 & 30 & 8 & 4 & 5 \\
\hline Popliteal artery & 11 & 19 & 7 & 2 & 2 \\
\hline Anterior tibial artery & & 31.5 & 10 & 5 & 3 \\
\hline Posterior tibial artery & 14 & 24.5 & 7 & 4 & 3 \\
\hline Peroneal artery & 13 & 23 & 4 & 6 & 3 \\
\hline Dorsalis pedis artery & 13 & 23 & 7 & 4 & 2 \\
\hline
\end{tabular}

This table and Fig. (2) show affected artries by CTA, the most affected artery was ATA which found in 18 patients, the second affected artery was SFA which found in 17 patients, the least affected arteries were CFA and PFA which found only in two patients.

The infra-popliteal arteries are more affected. 


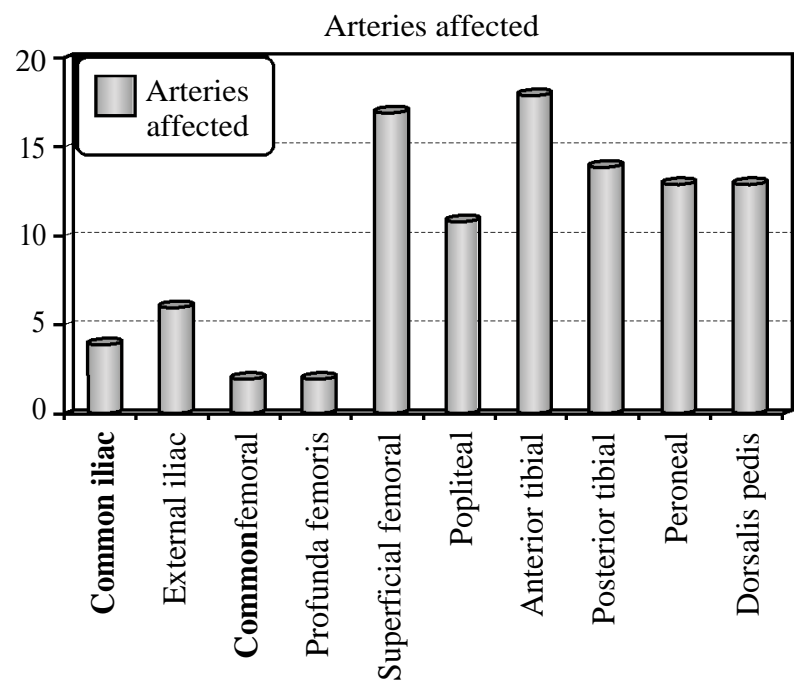

Fig. (2): Frequency of affected arteries in studied limbs by Doppler.

Table (5): Frequency of affected arteries in studied patients by Doppler study.

\begin{tabular}{llllll}
\hline & \multicolumn{1}{c}{$\begin{array}{c}\text { Patients } \\
\text { number } \\
(\mathrm{n}=30)\end{array}$} & & & Segment affection \\
\cline { 2 - 6 } Affected arteries & N \% & $\begin{array}{c}\text { Total } \\
\text { occ- } \\
\text { lusion }\end{array}$ & $\begin{array}{c}\text { Significant } \\
\text { stenosis } \\
>50 \%\end{array}$ & $\begin{array}{c}\text { Non- } \\
\text { significant } \\
\text { stenosis }\end{array}$ \\
\hline Common iliac artery & 2 & 3.5 & 1 & 0 & 1 \\
External iliac artery & 4 & 0 & 2 & 0 & 2 \\
Common femoral artery & 2 & 3.5 & 2 & 0 & 0 \\
Profunda femoris artery & 0 & 0 & 0 & 0 & 0 \\
Superficial femoral artery & 15 & 26 & 6 & 6 & 3 \\
Popliteal artery & 11 & 19 & 7 & 1 & 3 \\
Anterior tibial artery & 18 & 31.5 & 10 & 5 & 3 \\
Posterior tibial artery & 13 & 23 & 6 & 3 & 4 \\
Peroneal artery & 10 & 17.5 & 2 & 4 & 4 \\
Dorsalis pedis artery & 12 & 21 & 7 & 3 & 2 \\
\hline
\end{tabular}

This table and Fig. (2) show affected artrires by doppler ultrasound, the most affected artery was ATA which found in 18 patients, the second affected artery was SFA which found in 15 patients, the least affected arteries was PFA which couldnot be assessed.

In all arterial segments (ilio-femoro-popliteal and infra popliteal segment) calculated true positive, true-negative, false positive and false negative results are shown for detection accuracy, specificity and sensitivity of Doppler US compared to CTA and differentiate between significant and non significant stenosis.
Table (6): Accuracy of Doppler compared to CTA in diagnosis of different lesions in ilio-femoro-popliteal arteries in studied limbs.

\begin{tabular}{llcl}
\hline Artery & Sensitivity & Specificity & Accuracy \\
\hline Common iliac artery & $33.3 \%$ & $100 \%$ & $50 \%$ \\
External iliac artery & $40 \%$ & $100 \%$ & $50 \%$ \\
Common femoral artery & $100 \%$ & $0 \%$ & $100 \%$ \\
Profunda femoris artery & $0 \%$ & $0 \%$ & $0 \%$ \\
Superficial femoral artery & $83.3 \%$ & $60 \%$ & $76.4 \%$ \\
Popliteal artery & $88.9 \%$ & $100 \%$ & $90.9 \%$ \\
\hline
\end{tabular}

From this table, regarding ilio-femoro-popliteal segment the high sensitivity of Doppler US was present in CFA (100\%) then POPA (88.9\%) and less sensitivity of Doppler US was present in PFA $(0 \%)$.

Table (7): Accuracy of Doppler compared to CTA in diagnosis of different lesions in infra-popliteal arteries in studied limbs.

\begin{tabular}{lccc}
\hline Artery & Sensitivity & Specificity & Accuracy \\
\hline Anterior tibial artery & $100 \%$ & $100 \%$ & $100 \%$ \\
Posterior tibial artery & $90 \%$ & $75 \%$ & $86 \%$ \\
Peroneal artery & $60 \%$ & $100 \%$ & $70 \%$ \\
Dorsalis pedis artery & $90 \%$ & $100 \%$ & $92 \%$ \\
\hline
\end{tabular}

Regarding infrapopliteal arterial segment the high sensitivity of Doppler US was present in ant tibial A (100\%), the second artery was PTA and DPA (90\%) and less sensitivity of Doppler US was present in peroneal artery $(60 \%)$.

Table (8): Accuracy of Doppler compared to CTA in diagnosis of lower limb arterial disease in studied patients.

\begin{tabular}{cccc}
\hline & Sensitivity & Specificity & Accuracy \\
\hline Doppler & $81.2 \%$ & $90 \%$ & $83 \%$ \\
\hline
\end{tabular}

This table shows, the sensitivy of Doppler study was $81.2 \%$, specificity $90 \%$ and accuracy $83 \%$. 

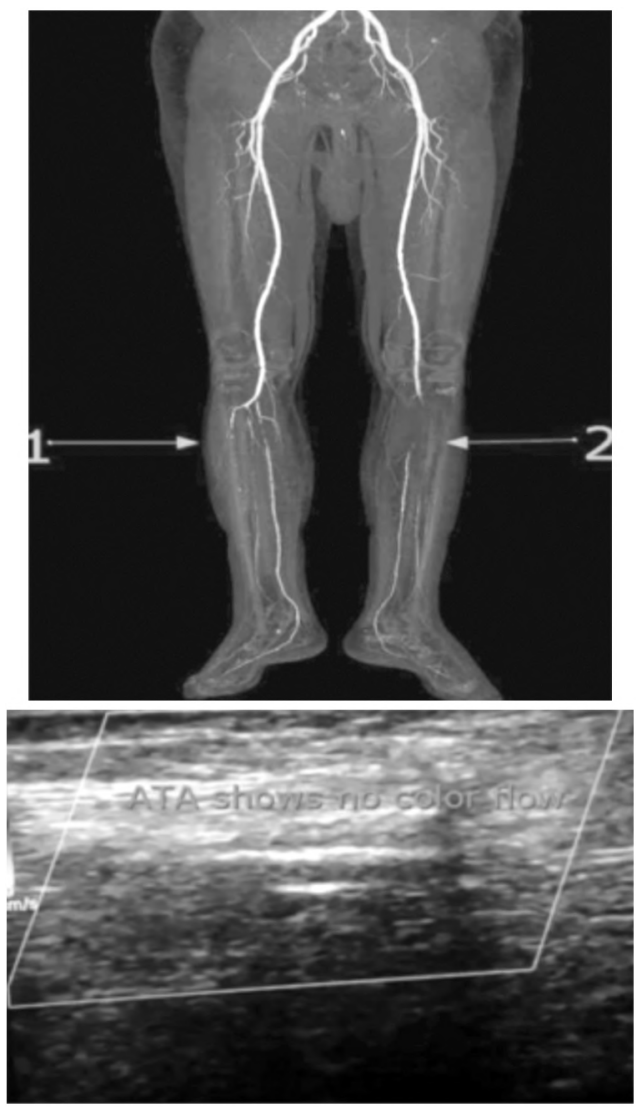
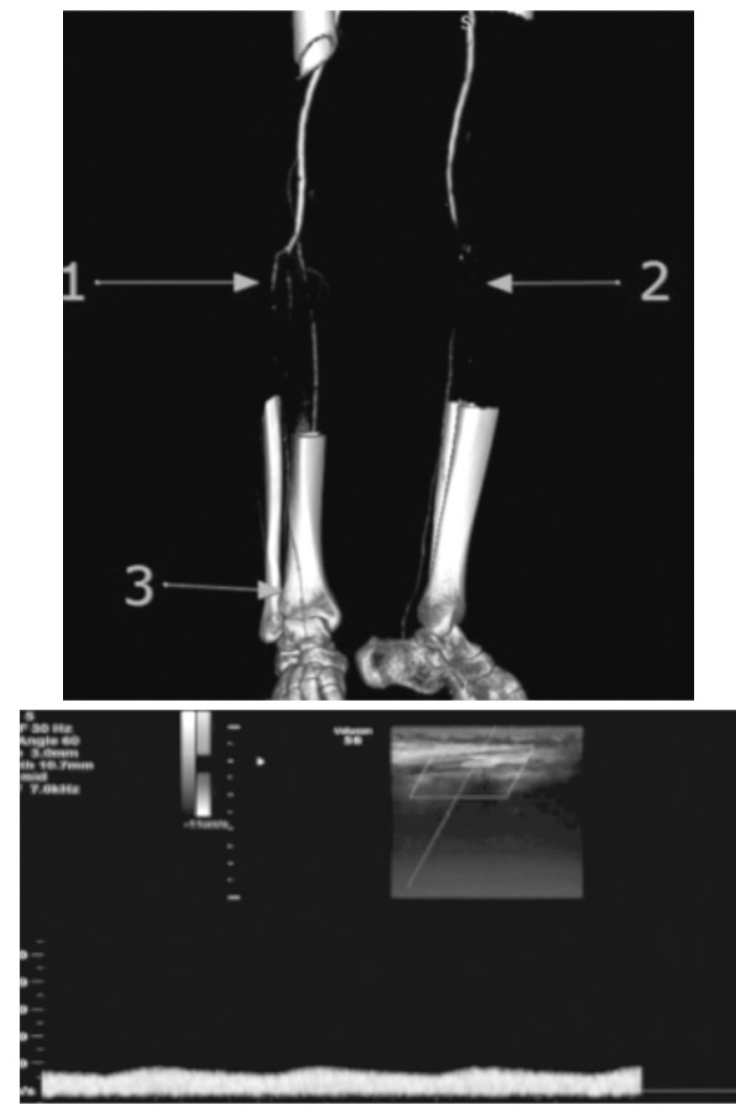

Fig. (3): Male 60 years old with medical DM, complaining of left diabetic foot with rest pain at calf muscles.

- CTA (MIP and VR) show:

- Left limb: Distal part of POPA is totally occluded, occluded tibioperoneal trunk, anterior tibial artery (2) and refilling of the posterior tibial artery about $5 \mathrm{~cm}$ after its origin then it appears patent down to the foot.

- Right limb: Markedly attenuated proximal segment of the posterior tibial artery (1) then it appears patent down to the foot and occluded anterior tibial artery shortly after its origin with refilling of the lower third and patent dorsalis pedis artery (3).

- Doppler study: Left ATA show no color flow and PTA show monophasic wave.
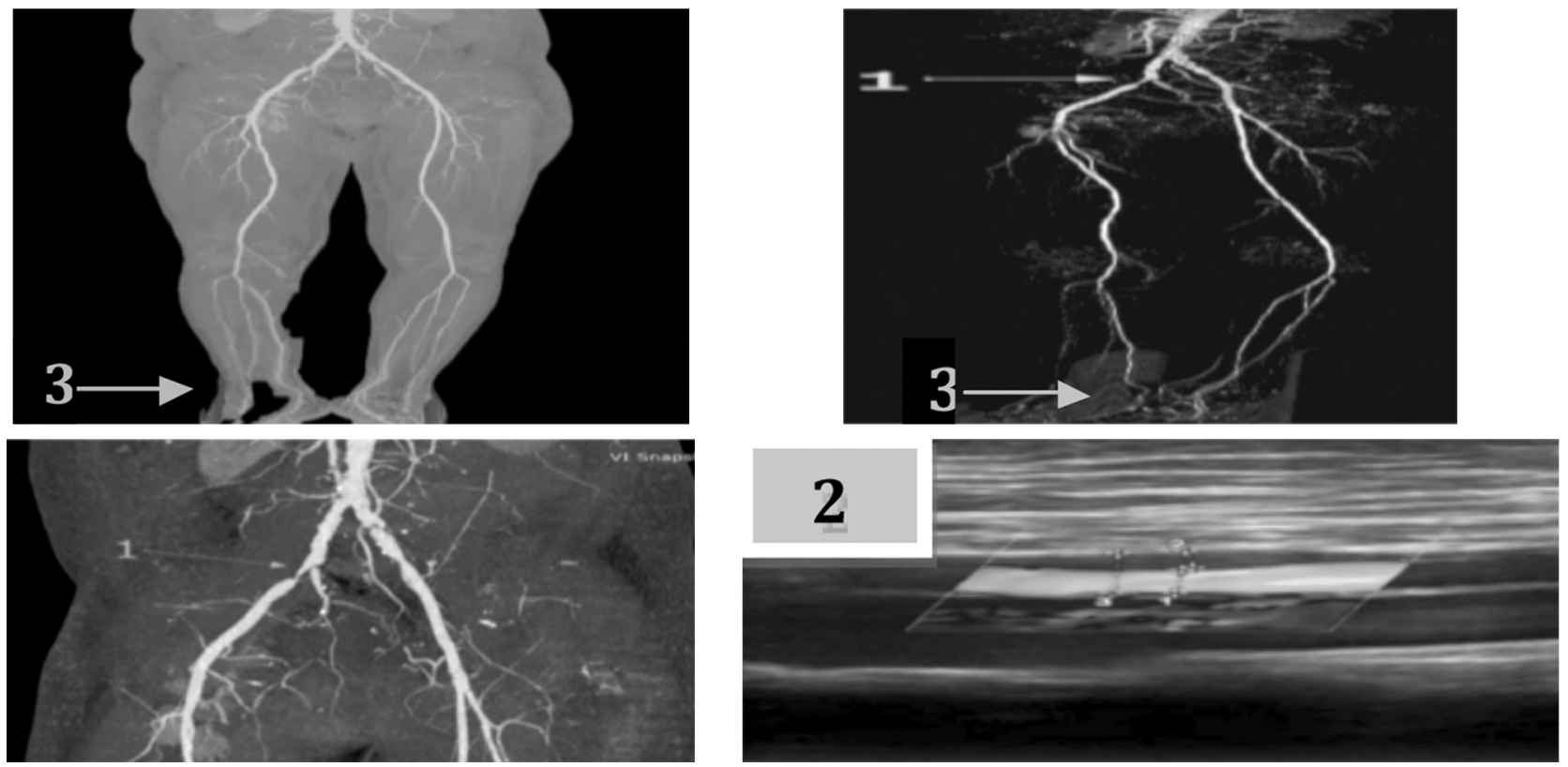

Fig. (4): Male pt 54 years old came with right diabetic foot and claudication pain at leg.

- CTA (VR and MIP) show short stenotic segment at begging of right external iliac artery (1) and attenuated Rt. ATA (3).

-2. Color duplex study of Rt SFA show non calcificed plaque with no significant stenosis. 

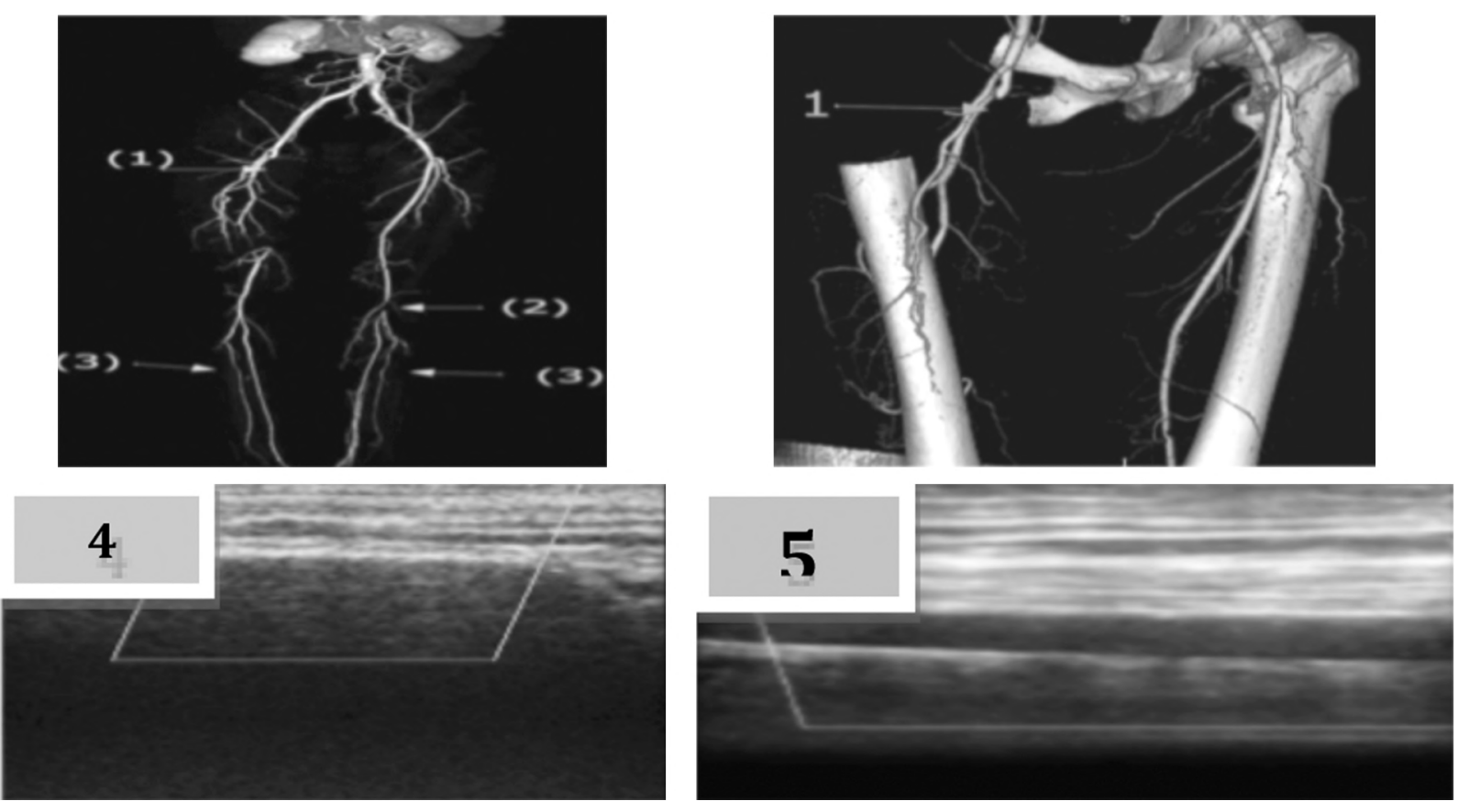

Fig. (5): Male patient 47 years old with right diabetic foot.

- CTA (MIP and VR) show right occluded SFA(1), short occluded segment of Lt. POPA (2) and bilateral occluded ATA and dorsalis pedis (3). - 4. Color duplex study of Rt. ATA shows no color flow.

- 5. Color duplex study of Rt. SFA shows no color flow.

\section{Discussion}

The purpose of the current study focused on the assessment of the role of MDCT angiography and Color Doppler Ultrasonography in diagnosis of diabetic foot infections which are among the most serious and frequent complications encountered in patients with diabetes mellitus.

This study included thirty patients had diabetic foot infection. 17 of the patients were males represent $56.6 \%$ and 13 were females represent $43.4 \%$. Their ages are mainly between $40-80$ years old with a mean age of $60.5 \pm 12$ years. This supported by Adam K.M. et al., [8] which reported that the occurrence of DFUs mostly in males and old aged subjects.

In the present study $(100 \%)$ of the patients were type II diabetes mellitus and had uncontrolled hyperglycemia with mean level $262 \pm 70 \mathrm{mg} / \mathrm{dl}$. This supported by Shailesh K. et al., [9] in a study of prevalence of diabetic foot ulcer and associated risk factors in diabetic patients, he found that uncontrolled glucose level delays wound healing and results in severity of ulcers and appearance of grade III and IV ulcers.

The reported clinical presentation in the thirty patients includes rest pain in six patients, intermittent claudication pain in twenty patients, minor tissue loss "ulceration" and persistent pain in ten patients, major tissue loss in three patients. The clinical effects vary with the site and the degree of vascular insufficiency. This is in accordance with the findings of the other studies which showed that the most common symptoms of PAD is Intermittent Claudication (IC). More extreme presentations of PAD include: Rest pain, tissue loss, or gangrene; these limb-threatening manifestations of PAD are collectively termed Critical Limb Ischemia (CLI). Among PAD patients without classic symptoms of IC, some are asymptomatic, other than IC (atypical leg pain) [10].

The aim of the present study was to illustrate the role of CTA as a non-invasive method in assessment of vasculature in patients with diabetic foot infection.

Fleischmann D. et al., [11] stated that, the principle goal of CTA is to evaluate the extent of disease and characterize vessel morphology as to distinguish lesions by type (i.e., atheromatus versus thromboembolic); occlusion; length (i.e. focal, short segment, long segment); vascular territory distribution. That CTA can offer a way to address treatment planning. For patients with lesions amenable to intervention, CTA also provides a road map, in particular target vessels for potential distal surgical anastomosis. 
In the present study the number of segments were 513 for 57 limbs, each arterial tree of one limb was divided into 9 segments (common iliac, external iliac,common femoral, superficial femoral, deep profunda,popliteal, anterior tibial, posterior tibial and peroneal).

Ozkan et al., [12] examined the segmental distribution of atherosclerosis in 626 symptomatic patients with peripheral arterial disease. Peripheral arterial disease involved one segment in $36 \%$ of the patients, two segments in $42 \%$ of the patients and three or more segments in $33.33 \%$ of the patients. He concluded that PAD was multisegmental in most of the cases of the study group this was similar to our results where PAD involved one segment in $30 \%$ of the patients, two segments in $36.66 \%$ of the patients and three segments in $33.33 \%$ of the patients.

In the present study twenty five cases out of thirty had arterial wall calcification ranging from mild arterial calcification to severe arterial wall calcification.

Ouwendijk R. et al., [13] found significant change in diagnostic accuracy and interobserver agreement in arterial segments with calcifications than in segments without calcifications and that, in these cases, patients could not be treated without undergoing DSA for accurate evaluation.

In this study, all cases underwent Doppler examination as a rapid, non-invasive complementary diagnostic tool and compared the findings with CTA.

Lingegowda et al., [14] in studying imaging modality in diabetic ischemic foot stated that when the diabetic patient presented with a non-healing ulcer, the investigation of choice should be duplex ultrasound. Ultrasound not only safe and noninvasive, it also serves to guide further patient management. Since ultrasound has high negative predictive value, no further investigation is required when duplex findings are normal.

In the present study Doppler ultrasound was done to all patients with diabetic foot infection, which helped in primary mapping of the vessels which was not accurate as MDCT due to some disadvantages as the patients status, presence of calcification, and deeply seated peroneal artery.

The study assessed the agreement between CTA findings and Doppler ultrasound findings regarding arteries of lower limbs on affected side. The studied arterial segments were classified into non-significant stenosis, stenotic and occluded.

In our study when colour doppler ultrasound was compared to MDCT in detecting peripherial arterial disease, MDCT was better in detecting these lesions.

In this study the main limitation was that DUS and MDCTA findings were not compared with DSA, which is considered being the gold standard technique in detecting lower extremities PAD. However it was not done in this study because of its invasive nature. Therefore, this result may under-estimate the percentage of arteries with lesions that are actually detectable in patients with PAD. However, results of several studies report MDCTA as a non-invasive alternative to DSA.

In this study it was agreed that CT angiography is more available, easier, less costly and also can be done to almost all patients, in the other side MRA was not done due to high cost and cannot be done to patient with pace maker and metallic stent.

MDCT angiography of the aorta and lowerextremity arteries in this study demonstrates that the technique is highly accurate and has potential to substitute in most cases for DSA and MRA. As CT scan is generally easier to perform, more widely available, and can be obtained more rapidly than MRA and DSA. It is usually preferred in the emergent setting.

\section{Conclusion:}

The usage of CTA increases the ability for delineation of vascular anatomy, it can localize the obstruction, assess the severity stenosis, detect the presence of collaterals and distal run off which helps in planning for management of peripheral arterial disease.

Doppler ultrasonograpy is a reliable noninvasive method of investigating the lower limb arterial system. It provides us with hemodynamic data proximal, distal and at the site of obstruction.

This studty leads us to the conclusion that MDCT angiography may replace color Doppler sonography in many cases.

Conflicts of interest: There are no conflicts of interest.

\section{References}

1- BERENDT A.R., PETERS E.J., BAKKER K., et al.: Diabetic foot osteomyelitis: A progress report on diagnosis and a systematic review of treatment. Diabetes Metab. Res. Rev., 24 (suppl 1): S145-S161, 2008. 
2- TOMIC-CANIC M. and BREM H.: Gene array technology and pathogenesis of chronic wounds. Am. J. Surg., 188 (1A Suppl): 67-72, 2004.

3- POMPOSELLI F.: Arterial imaging in patients with lower extremity ischemia and diabetes mellitus. J. Vasc. Surg., 52 (3 Suppl): 81 S-91 S, 2010.

4- LINDNER J.R., WOMACK L., BARRETT E.J., WELTMAN J., PRICE W., HARTHUN N.L., et al.: Limb stressrest perfusion imaging with contrast ultrasound for the assessment of peripheral arterial disease severity. JACC Cardiovasc Imaging, May, 1 (3): 343-50, 2008.

5- GABRIEL M., PAWLACZYK K., SZAJKOWSKI R., STEFANIAK K., DZIECIUCHOWICZ L. and KRASINSKI Z.: The use of duplex ultrasound arterial mapping (DUAM) and pre-operative diagnostics in patients with atherosclerotic ischaemia of lower extremities. Pol. Przegl. Chir., 84 (6): 276-84, 2012.

6- HEIJENBROK-KAL M.H., KOCK M.C. and HUNINK M.G.: Lower extremity arterial disease: Multidetector CT angiography metaanalysis. Radiology, 245: 433-9, 2007.

7- BUI B.T., MILLER S., MILDENBERGER P., SAM A 2nd and SHENG R.: Comparison of contrast-enhanced MR angiography to intraarterial digital subtraction angiography for evaluation of peripheral arterial occlusive disease. J. Magn. Reson. Imaging, 31 (6): 1402-10, 2010.

8- ADAM K.M., MAHMOUD S.M., MAHADI S.I., WIDATALLA A.H., SHAWER M.A. and AHMED M.E.: Ex- tended leg infection of diabetic foot ulcers: Risk factors and outcome. J. Wound Care, 20: 440-4, 2011.

9- SHAILESH K., SHAHI M.S., ASHOK KUMAR M.S. and SUSHIL KUMAR M.: Prevalence of Diabetic Foot Ulcer and Associated Risk Factors in Diabetic Patients From North India. J. Diabet. Foot Comp., 4: 83-91, 2012.

10-McDERMOTT M.M., GREENLAND P., LIU K., GURALNIK J.M., CRIQUI M.H. and DOLAN N.C.: Leg symptoms in peripheral arterial disease: Associated clinical characteristics and functional impairment. JAMA 3, 286: 1599-606, 2001.

11- FLEISCHMANN, RICHARD L. HALLETT and GEOFFREY D. RUBIN: CT Angiography of Peripheral Arterial Disease: Vasc. Interv. Radiol., 17: 3-26, 2006.

12- OZKAN U., OGUZKURT L. and TERCAN F.: Atherosclerotic risk factors and segmental distribution in symptomatic peripheral artery disease. J. Vasc. Interv. Radiol., Apr., 20 (4): 437-41, 2009.

13- OUWENDIJK R., KOCK M.C., VISSER K., PATTYNAMA P.M., De HAAN M.W. and HUNINK M.G.: Interobserver agreement for the interpretation of contrastenhanced 3D MR angiography and MDCT angiography in peripheral arterial disease. A.J.R. Am. J. Roentgenol., 185: 1261-7, 2005

14- LINGEGOWDA D., MOORTHY S. and SREEKUMAR K.P.: Imaging in diabetic ischemic foot. Int. J. Diabetes Dev. Ctries., 30: 179-85, 2012. 


\section{دور الآثعة المقطعية لتصوير الآوعية والدوبلر الملون فى تقييم الشرايين بالقدم السموير السكرى}

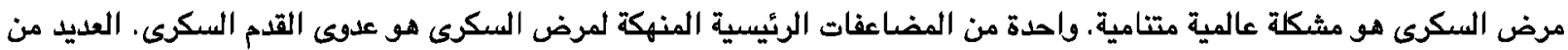

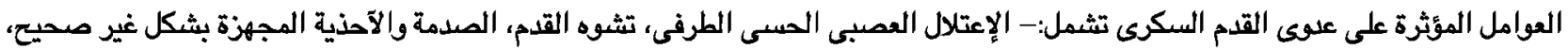

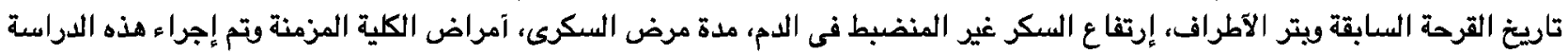

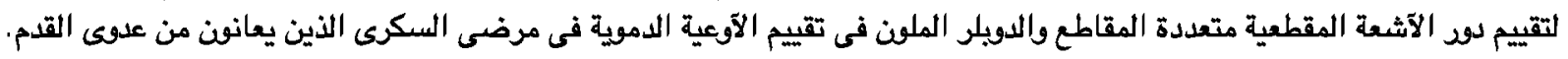

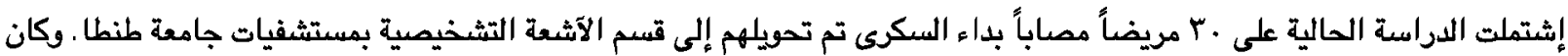

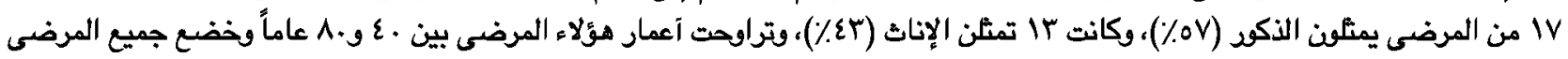

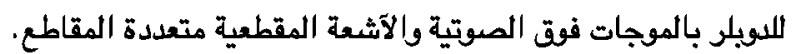

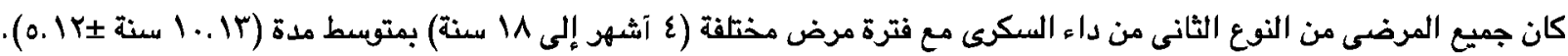

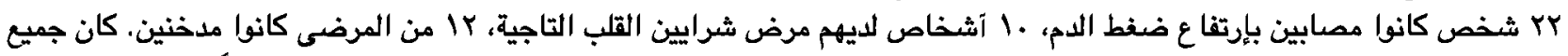

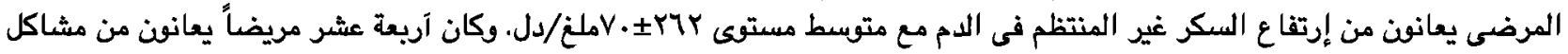
بطرق سفلى واحل وستة عشر من مشاكل بالطرفين السفليين.

المرضى الثلاثين جائوا بشكاوى مختلفة: آلام فى الآطراف السفلية بدقن بذل مجهود (ستة آثخاص)، آلام متقطعة فى الآطراف السفلية

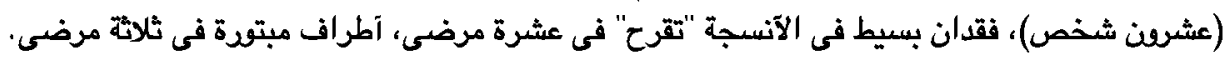

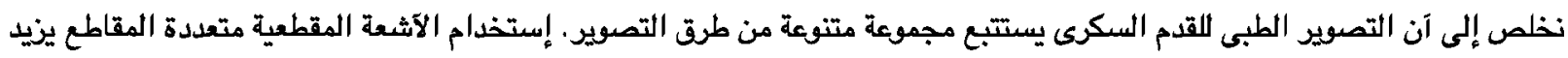

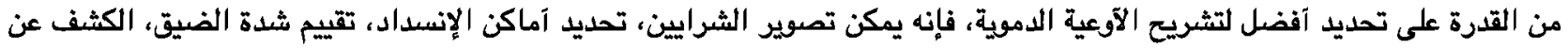
وجود مسارات آخرى اللدم مما يساعد فى التخطيط لإدارة آمراض التهرية الشرايين الطرفية.

يعد فصص CTA بشكل عام غير جائر، ويسهل تنفيذه، ومتوفر على نطاق واسع، ويمكن الحصل عليه بسرعة آكبر من الرنين المغناطيسى والتصوير الإشعاعى الرقمى.

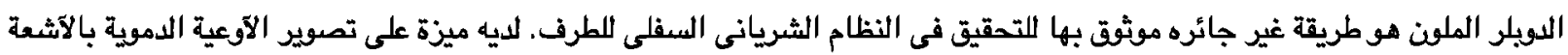

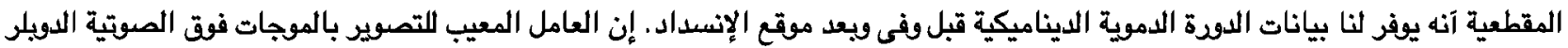

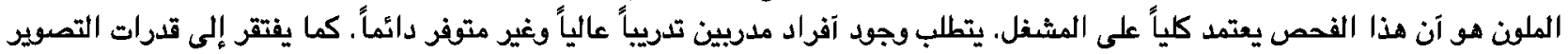

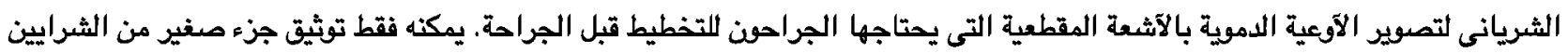
فى كل صودة. هذا يقودنا إلى إستنتاج آن تصوير الآوعية الدموية بالآشعة المقطعية قد يحل محل التصوير بالموجات فوق الصوتية دوبلر اللهن في كثير الحالات. 